\title{
SMR
}

Short Communication

\section{A small B chromosome in the grasshopper Ommexecha virens (Ommexechidae)}

\author{
T.E. Souza' ${ }^{1}$, L.C. Silva-Neto ${ }^{2}$, J.F. Santos ${ }^{1}$, V. Loreto ${ }^{2}$ and T.T. Rieger ${ }^{1}$ \\ ${ }^{1}$ Laboratório de Experimentação em Drosophila, Departamento de Genética, \\ Universidade Federal de Pernambuco, Recife, PE, Brasil \\ 'Laboratório de Genética e Citogenética Animal, Departamento de Genética, \\ Universidade Federal de Pernambuco, Recife, PE, Brasil \\ Corresponding author: T.E. Souza \\ E-mail: tyago_eufrasio@yahoo.com.br
}

Genet. Mol. Res. 14 (4): 17505-17510 (2015)

Received July 24, 2015

Accepted October 8, 2015

Published December 21, 2015

DOI http://dx.doi.org/10.4238/2015.December.21.22

ABSTRACT. B chromosomes, also called supernumerary or accessory chromosomes, have been characterized as extra elements found in the karyotypes of different eukaryotic species. B chromosomes are nonvital and only occur in some individuals within a species. Moreover, the chromosomes contain silenced genes, and they exhibit heterochromatinization and the accumulation of repetitive DNA and transposons. In the present study, we describe an extra chromosome in the grasshopper Ommexecha virens for the first time, using conventional staining and fluorescent in situ hybridization techniques, and we discuss the possible origin of the $B$ chromosome.

Key words: B chromosome; Fluorescent in situ hybridization; Grasshopper; Ommexechidae 


\section{INTRODUCTION}

Supernumerary chromosomes (B chromosomes) are extra elements, not homologous to the standard complement and present in several species of plants and animals. In insects, occur mainly in Diptera, Coleoptera and Orthoptera (Loreto et al., 2008). They may have different origins, including the derivation of autosomal (Jamilena et al., 1995), sexual chromosomes (LopezLeon et al., 1994) and resulting from interspecies crosses (Mcallister and Werren, 1997). The molecular mechanisms that drive the evolution of these segments resemble that of univalent sex chromosomes, as gene silencing and heterochromatinization processes (Camacho et al., 2000). B chromosomes are nonvital and only occur in some individuals within a species. Furthermore, they typically have accumulation mechanisms that increase their transmission prior to, during, or following gametogenesis (Nur, 1977). They are often heterochromatic, and do not pair and recombine with any of the $A$ chromosomes during meiosis. Moreover, the chromosomes usually do not contain major genes, with the exception of ribosomal DNA (rDNA) sequences, which have been mapped on many plant and animal B chromosomes (Jones, 1995). About the grasshoppers species that present B chromosome, Eyprepocnemis plorans is among the most studied. This species has forty types of $\mathrm{B}$ variants along the populations found in the Mediterranean and Atlantic coasts of the Iberian Peninsula and North Africa (Cabrero et al., 1999). Loreto et al. (2008) investigated the possible origin of macro B chromosome in Rhammatocerus brasiliensis and Xyleus discoideus angulatus populations originated in Northeastern region of Brazil. In these species, the B chromosome proved very similar to the $\mathrm{X}$ chromosome in morphology. However, the FISH results show an autosomal origin of these chromosomes.

The Ommexecha genus presents the major geographical distribution among Ommexechidae, which is found from East of the Andes to the Caribbean and Northeastern Brazil. Of the six known species, only O. virens presents great phenotypic (morphologic and chromatic) variability (Mesa and Ferreira, 1977). The O. virens karyotype was characterized using conventional staining, C-banding, silver nitrate impregnation, base specific fluorochromes and fluorescent in situ hybridization (FISH) with 18S rDNA probe (Carvalho et al., 2011). A total of $2 n=23$ chromosomes were found in this species, which exhibited predominantly acrocentric morphology, with the exception of submetacentric $L 1$ and the $X 0: X X$ sexual mechanism. The karyotype is generally arranged as three pairs of large chromosomes (L1 to L3), five pairs of medium chromosomes (M4 to M8), three pairs of small chromosomes (S9 to S11), and an X chromosome (considered mediumsized). In this study, we present the first description of an extra chromosome in an Ommexechidae representative, and discuss the possible origin of the B chromosome in $O$. virens.

\section{MATERIAL AND METHODS}

A total of 115 O. virens individuals, collected in Pernambuco (PE) and Bahia (BA) states in Northeast Brazil (Table 1), were analyzed. The testes and ovaries were fixed in Carnoy's solution (3:1 ratio of ethanol and acetic acid), and the cytological preparations were obtained via the squashing follicles technique. For conventional analysis, the slides were stained with $1 \%$ lacto-acetic orcein. $\mathrm{CMA}_{3} / \mathrm{DA} / \mathrm{DAPI}$ staining was accomplished following the methods specified by Schweizer et al. (1983). DNA extractions for fluorescent in situ hybridization (FISH) preparations were performed following the methods specified by Walsh et al. (1991). Approximately 1 to 2 testicular follicles were homogenized in $10 \%$ Chelex, and were subsequently subjected to $56^{\circ}$ and $96^{\circ} \mathrm{C}$ water baths. 
The material was then centrifuged at $13,000 \mathrm{rpm}$, and the supernatant was stored at $-20^{\circ} \mathrm{C}$ prior to polymerase chain reaction (PCR) analysis. The 5S rDNA, 18S rDNA, and $\mathrm{H} 3$ histone gene probes were obtained using PCR. To amplify the genes of interest, we used the following primers: 5'-AACGACCATACCACGCTGAA-3' and 5'-AAGCGGTCCCCCATCTAAGT-3' for the 5S rDNA gene; 5'-CCCCGTAATCGGAATGAGTA-3' and 5'-GAGGTTTCCCGTGTTGAGTC-3' for the 18S rDNA gene; 5'-ATATCCTTRGGCATRATRGTGAC-3' and 5'-ATGGCTCGTACCAAGCAGACVGC-3' for the $\mathrm{H} 3$ histone gene. The FISH analysis was done according to the methods of Moscone et al. (1996); using the $18 \mathrm{~S}$ and $5 \mathrm{~S}$ rDNA and $\mathrm{H} 3$ histone probes. A stringency level of $72 \%$ was determined after three washes in $2 X S S C$ at $42^{\circ} \mathrm{C}$, two washes in $0.1 X S S C$ at $42^{\circ} \mathrm{C}$, and one wash in $2 \mathrm{X} \mathrm{SSC}$ at $25^{\circ} \mathrm{C}$ (5 min each). The $\mathrm{FISH}$ and fluorochrome procedures were conducted using materials from two specimens with $B$ chromosomes (1B) and two specimens without $B$ chromosomes (OB). Photographs were obtained by Leica CW4000 FISH capture system coupled to a Leica DMLB fluorescent microscope. The figures were mounted with the use of the Adobe Photoshop CS5 Extended software.

\section{RESULTS AND DISCUSSION}

The karyotypes of analyzed $O$. virens populations were described by Carvalho et al. (2011), but the presence of B chromosomes in the Sobradinho (BA) population was not included (Table 1). In this population, a small B chromosome, which was similar to the S9 pair both in size and acrocentric morphology, was visualized in $16 \%$ of the individuals studied. In other grasshopper populations, such as Melanoplus femur-rubrum (Nur, 1977), Eyprepocnemis plorans (Henriques-Gil et al., 1984), and Rhammatocerus brasiliensis (Loreto et al., 2008), B chromosome prevalence was similar (10\%, 10 to $15 \%$, and 6.5 to $17.9 \%$, respectively). In populations where the $B$ chromosome recently emerged, the frequency was usually high (>25\%) (Araújo et al., 2001). On the other hand, in the case of B chromosome stability or extinction, this number was relatively low (Riera et al., 2004). The $16 \%$ frequency in the Sobradinho population may be an indication that the origin of this $\mathrm{B}$ chromosome is not recent.

The small $\mathrm{B}$ chromosome of $\mathrm{O}$. virens exhibits picnosis similar to that of the chromosomal complement pairs, with the exception of $X$ (Figure 1a). The other analyzed populations did not exhibit B chromosomes (Table 1).

Table 1. Localities of collections with geographical coordinates in the States of Pernambuco (PE) and Bahia (BA) in the Northeastern region of Brazil, and the number of individuals analyzed and $1 \mathrm{~B}$ individuals of Ommexecha virens populations studied.

\begin{tabular}{llcr}
\hline Localities & Coordinates & Number of individuals analyzed & Number of 1B individuals \\
\hline Sobradinho - BA & $9^{\circ} 27^{\prime} 19 " \mathrm{~S} ; 40^{\circ} 49^{\prime} 24^{\prime \prime} \mathrm{W}$ & 25 & 4 \\
Buíque - PE & $8^{\circ} 37^{\prime} 23^{\prime \prime} \mathrm{S} ; 37^{\circ} 9^{\prime} 12$ 'W & 24 & 0 \\
Rio de Contas - BA & $13^{\circ} 34^{\prime} 44^{\prime \prime S}$; $41^{\circ} 48^{\prime} 41^{\prime \prime}$ & 21 & 0 \\
Andaraí - BA & $12^{\circ} 48^{\prime} 26^{\prime \prime S} ; 41^{\circ} 19^{\prime} 53^{\prime \prime} \mathrm{W}$ & 23 & 0 \\
Mucugê - BA & $13^{\circ} 0^{\prime} 19^{\prime \prime} \mathrm{S} ; 41^{\circ} 22^{\prime} 45^{\prime \prime} \mathrm{W}$ & 22 & 0 \\
\hline
\end{tabular}

The $5 \mathrm{~S}$ rDNA sites were preferentiality present in the pericentromeric/proximal region of the four largest autosomal pairs (L1, L2, L3, and M4). However, a 5S rDNA site was also identified in the L3 terminal region. In L2, the 5S rDNA site collocated with the 18S rDNA site. The 1B individuals did not have the $5 S$ rDNA site in the extra chromosome, and the $5 S$ rDNA localization 
pattern was the same as that in $\mathrm{OB}$ individuals. The results indicated variation in the number of $5 S$ rDNA sites in both individuals (Figure 1b, c), and this was observed in other grasshopper species both with and without B chromosomes (Cabral-de-Mello et al., 2011). The O. virens $18 \mathrm{~S}$ rDNA analysis was previously performed by Carvalho et al. (2011) in OB individuals, and it was conducted in the present study to compare the possible $18 \mathrm{~S}$ sites in 1B individuals. The 18S rDNA sites were observed in the pericentromeric/proximal regions of the L2, S9, and S10 chromosomes (Figure $1 \mathrm{~b}, \mathrm{c}$ ), and the pattern of $18 \mathrm{~S}$ rDNA sites was the same in $\mathrm{OB}$ and $1 \mathrm{~B}$ individuals. The $\mathrm{H} 3$ histone site was only seen at the proximal location of the $\mathrm{S} 9$ chromosomes of both $\mathrm{OB}$ and $1 \mathrm{~B}$ specimens (Figure 1d, e), but the B chromosome did not present rDNA or histone sites (Figure 1h). The chromosome location of the $\mathrm{H} 3-\mathrm{H} 4$ histone gene clusters exhibited high regularity in grasshopper families. Thirty-five Acrididae species analyzed by Cabrero et al., 2009 exhibited a single $\mathrm{H} 3-\mathrm{H} 4$ cluster in an autosome only, which in most cases is the third chromosomal pair. In four Proscopiidae grasshopper species, the number and location of the $\mathrm{H} 3$ histone genes were highly conserved, and only one site was present on the fourth chromosome (Cabral-de-Mello et al., 2011). In Romaleidae, the $\mathrm{H} 3$ histone gene distribution pattern in four species was observed for the first time. The $\mathrm{H} 3$ histone site was restricted to the second autosomal pair in all species examined (Neto et al., 2013).

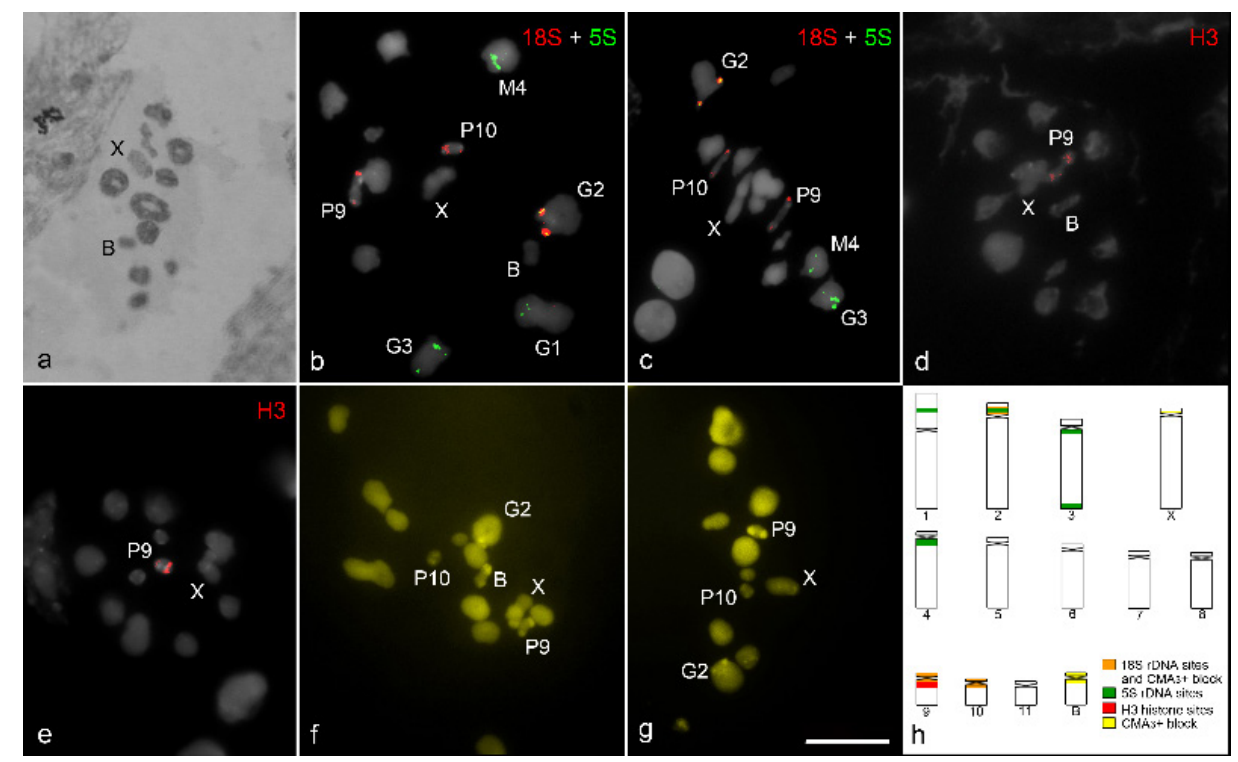

Figure 1. Characterization of $B$ chromosomes in Ommexecha virens. (a) Conventional staining of metaphase I from an individual bearing 1B. Locations of $5 \mathrm{~S}$ and $18 \mathrm{~S}$ rDNA in (b) $1 \mathrm{~B}$ and (c) OB individuals. The $5 \mathrm{~S}$ rDNA sites (green) are in the L1, L2, L3, and M4 pairs, and the 18S rDNA sites (red) are in L2, S9, and S10 pairs. H3 histone sites in S9 are shown in (d) and (e). $\mathrm{CMA}_{3}$-positive blocks are shown in (f) $1 \mathrm{~B}$ and $(\mathbf{g}) \mathrm{OB}$. Note a similar pattern between $\mathrm{S} 9$ and B. (h) Idiogram showing $5 \mathrm{~S} / 18 \mathrm{~S}$ rDNA, $\mathrm{H} 3$ histone, and $\mathrm{CMA}_{3}$-positive block distribution patterns in the chromosomal complement. Bar $=10 \mu \mathrm{m}$.

Regarding $\mathrm{CMA}_{3} / \mathrm{DA} / \mathrm{DAPI}$ staining, $\mathrm{CMA}_{3}$ positive blocks were observed in the pericentromeric regions of the $\mathrm{L} 2, \mathrm{~S} 9$, and $\mathrm{S} 10$ chromosomal pairs in $\mathrm{OB}$ and $1 \mathrm{~B}$ individuals. The small $\mathrm{B}$ chromosome showed a $\mathrm{CMA}_{3}$ pattern that was similar to that of the $\mathrm{S} 9$ chromosome 
(Figure 1f, g). However, the presence of the $18 \mathrm{~S} / \mathrm{H} 3$ sites observed in the S9 pair was not indicated. Based on the data obtained (Figure 1h), if the small B chromosome observed in O. virens originated from the S9 chromosome, it suffered some rearrangements that led to the loss of the 18S rDNA and H3 histone sites present in S9. According to Camacho et al. (2000), B chromosomes may originate from sex chromosomes. In the grasshopper Xyleus discoideus angulatus (Romaleidae), the $\mathrm{B} X$ chromosomes have highly similar morphology, size, and picnosis, but they differed when examined using other techniques (e.g., C-banding and FISH using 5S rDNA) (Loreto et al., 2008). In the case of $X . d$. angulatus, $\mathrm{L} 3$ and $\mathrm{X}$ chromosomes were excluded as probable $\mathrm{B}$ ancestors. In $\mathrm{O}$. virens, a probable autosomal origin of the $\mathrm{B}$ chromosome was supported, since there was no correspondence in the morphological aspects, FISH, and fluorochrome sites between $\mathrm{B}$ and $\mathrm{X}$ chromosomes. Therefore, the most likely origin of the $\mathrm{O}$. virens $\mathrm{B}$ chromosome is the $\mathrm{S} 9$ chromosome. If this is the case, the lack of similar repetitive DNA sites indicates that this origin of the B chromosome could be more ancient than indicated by its frequency and genomic disequilibrium. However, we did not entirely reject the possibility of the $\mathrm{B}$ chromosome originating from another chromosome. The circumscription to a unique population may be the result of limited migration of individuals among populations. This is the first report of a B chromosome in the Ommexechidae family, but it will be necessary to use other markers in order to more precisely establish the origin of the B chromosome in O. virens.

\section{Conflicts of interest}

The authors declare no conflict of interest.

\section{ACKNOWLEDGMENTS}

The authors would like to thank Edital Reuni-UFPE No. 01/2012 and Conselho Nacional de Desenvolvimento Científico e Tecnológico (CNPq) for fellowships awarded to T.E. Souza.

\section{REFERENCES}

Araújo SMSR, Pompolo SG, Perfectti F and Camacho JPM (2001). Integration of a B chromosome into the A genome of a wasp. Proc. Biol. Sci. 268: 1127-1131.

Cabral-de-Mello DC, Martins C, Souza MJ and Moura RC (2011). Cytogenetic mapping of 5 S and 18S rRNAs and H3 histone genes in 4 ancient Proscopiidae grasshopper species: contribution to understanding the evolutionary dynamics of multigene families. Cytogenet. Genome Res. 132: 89-93.

Cabrero J, López-León MD, Bakkali M and Camacho JPM (1999) Common origin of B chromosome variants in the grasshopper Eyprepocnemis plorans. Heredity 83: 435-439.

Cabrero J, López-León MD, Teruel M and Camacho JPM (2009). Chromosome mapping of H3 and H4 histone gene clusters in 35 species of acridid grasshoppers. Chromosome Res. 17: 397-404.

Camacho JPM, Sharbel TF and Beukeboom LW (2000). B-chromosome evolution. Philos. Trans. R. Soc. Lond. B. Biol. Sci. 355: 163-178.

Carvalho DB, Rocha MF, Loreto V, Silva AEB, et al. (2011). Ommexecha virens (Thunberg, 1824) and Descampsacris serrulatum (Serville, 1831) (Orthoptera, Ommexechidae): karyotypes, constitutive heterochromatin and nucleolar organizing regions. Comp. Cytogenet. 5: 123-132.

Henriques-Gil N, Santos JL and Arana P (1984). Evolution of a complex B-chromosome polymorphism in the grasshopper Eyprepocnemis plorans. Chromosoma 89: 290-293.

Jamilena M, Garrido-Ramos M, Ruiz-Réjon M, Ruiz-Réjon C, et al. (1995) Characterization of repeated sequences from microdissected B chromosomes of Crepis capillaris. Chromosoma 104: 113-120.

Jones RN (1995). B chromosomes in plants. New Phytol. 131: 411-434.

López-León MD, Neves N, Schwarzacher T, Heslop-Harrison JS, et al. (1994) Possible origin of a B chromosome deduced

Genetics and Molecular Research 14 (4): 17505-17510 (2015)

CFUNPEC-RP www.funpecrp.com.br 
from its DNA composition using double FISH technique. Chromosome Res. 2: 87-92.

Loreto V, Cabrero J, López-León MJ, Camacho JPM, et al. (2008) Possible autosomal origin of macro B chromosomes in two grasshopper species. Chromosome Res. 16: 233-241.

Mcallister BF and Werren JH (1997) Hybrid origin of a B chromosome (PSR) in the parasitic wasp Nasonia vitripennis. Chromosoma 106: 243-253.

Mesa A and Ferreira A (1977). Cytological studies in the family Ommexechidae (Orthoptera: Acridoidea). Acrida 6: 261-271.

Moscone EA, Matzke MA and Matzke AJM (1996). The use of combined FISH/GISH in conjunction with DAPI counterstaining to identify chromosomes containing transgene inserts in amphidiploid tobacco. Chromosoma 105: 231-236.

Neto MS, Souza MJ and Loreto V (2013). Chromosomal evolution of rDNA and H3 histone genes in representative Romaleidae grasshoppers from northeast Brazil. Mol. Cytogenet. 6: 41.

Nur U (1977). Maintenance of a parasitic B chromosome in the grasshopper Melanoplus femur-rubrum. Genetics 87: 499-512.

Riera L, Petitpierre E, Juan C, Cabrero J, et al. (2004). Evolutionary dynamics of a B chromosome invasion in island populations of the grasshopper Eyprepocnemis plorans. J. Evol. Biol. 17: 716-719.

Schweizer D, Mendelak M, White MJD and Contreras M (1983). Cytogenetics of the parthenogenetic grasshopper Warramaba virgo and its bisexual relatives. Chromosoma 88: 227-236.

Walsh PS, Metzger DA and Higuchi R (1991). Chelex 100 as a medium for simple extraction of DNA for PCR-based typing from forensic material. Biotechniques 10: 506-513. 